\title{
Reducing infant mortality rate a challenge in Liberia
}

Published at www.cmaj.ca on Sept. 3

I $\mathrm{n}$ the shade of a tree outside a special clinic for malnourished children, 20-year-old Ma-Kulah Turray reflects on how lucky her 6-month-old baby is to be alive.

Fed only dry rice and water for his first few months, the child quickly became malnourished and was nearly dead by the time Turray arrived at the hospital, telling staff she was not equipped to fix whatever was wrong with her baby.

"I need training on how to care for my child," says Turray, who is in the eighth grade. "I was leaving him alone while I went to school, so he was not getting enough food and no healthy food."

The education system ground to a halt during the west African country's 14-year civil war, which ended in 2003. A push to complete the education of young adults has driven many, like Turray, back into the classroom. But in doing so, Turray inadvertently risked her baby's life.

Malnutrition is among the leading causes of infant death in Liberia. This clinic in Tubmanburg, a county capital, takes in up to 30 malnourished children each month to nurse them back to health while providing their mothers with training on how to feed and care for their children.

"We are not having a crisis like we did during the war, but many people do not know malnutrition is caused by lack of adequate food," says Yvonne Jackson, program manager for the malnutrition clinic at Liberia Government Hospital in Tubmanburg. "Some of the mothers do not know how to prepare food or which food prevents malnutrition."
Turray and her boy are among the fortunate. Liberia's under-five mortality rate remains among the five highest in the world, and more than $15 \%$ of children die before reaching their first birthday, according to UNICEF.

But at the G8 meeting in Huntsville, Ontario, in June, Canadian Prime Minister Stephen Harper obtained a five-year, US\$5-billion pledge from G8 countries, along with US\$2.3 billion from others, to reach several targets by 2015 . The agreement calls for under-five mortality rates to be cut to two-thirds of 1990 levels and for maternal mortality rates to be cut to three-quarters of 1990 levels over the next five years. The countries also pledged to reach universal access to reproductive health.

The goals are ambitious, as illustrated by Liberia, a small country with a history of instability and conflict dating back to a 1979 coup and whose health indicators suggest is exactly the type of setting the G8 pledge targets.

On each of the three goals in the pledge - under-five mortality, maternal mortality and universal access to reproductive health - Liberia ranks among the world's most challenged.

Besides having one of the five highest infant mortality rates, maternal mortality rates nearly doubled to 994 deaths per 100000 live births between 2000 and 2007, and fewer than half of births in Liberia are attended to by health professionals.

Addressing those challenges in Liberia requires a big picture approach that takes into account systemic understaffing, underfunding and the effect of a civil war that devastated both infrastructure and the education system.

Liberian President Ellen Johnson Sirleaf - Africa's first female elected head of state - has made reproductive health among her priorities as part of a strategy called "Reach Every Pregnant Woman." The plan aims to provide equipment to clinics and hospitals, and training for staff. It also trains traditional midwives in rural areas where the closest clinic or hospital may be days away on foot or communities are inaccessible by road.

What remains unclear, though, is how and where G8 support will be administered. Each country pledged varying amounts to be committed over varying time lengths and in varying regions (Canada has said its $\$ 1.1$ billion share will be focused on countries it has identified as aid priorities: Haiti, Afghanistan, Mali, Tanzania and Mozambique).

Some maternal and child health advocates, who had hoped G8 leaders would commit to much more than $\$ 5$ billion (CMAJ 2010;DOI:10.1503 /cmaj.109-3303 and CMAJ 2010;DOI: 10.1503/cmaj.109-3300), are lobbying for the money to be channeled through large international bodies such as the World Bank and UNICEF. Others argue the money should go directly to the health care budgets of countries such as Liberia which have high infant and maternal mortality rates.

Among the other significant challenges facing G8 countries will be how to ensure their commitments actually benefit the individuals whose lives illustrate the global statistics.

"I hope to never have to return to this clinic," says Turray. "I want to help other mothers in my community to care for their children." - Christopher Mason, Tubmanburg, Liberia

DOI:10.1503/cmaj.109-3359 